\title{
Endoscopic Polypectomy Using Double-balloon Enteroscopy is Useful for the Treatment of Peutz-Jeghers Syndrome Even in Children
}

\author{
Tatsuya Mikami ${ }^{a}$, Yoshihiro Sasaki ${ }^{b}$, Tadashi Shimoyama, d, Manabu Sawaya ${ }^{a}$, \\ Norihiro Hanabata ${ }^{a}$, Hiroshi Kijima ${ }^{c}$, Shinsaku Fukuda ${ }^{a}$
}

\begin{abstract}
Patients suffering Peutz-Jeghers syndrome (PJS) have had to undergo frequent laparotomies because of intestinal obstruction by small intestinal hamartomatous polyps. Double-balloon enteroscopy (DBE) is now a useful device for the treatment of small intestinal polyps in adults. Here we report a successful use of DBE in the case of small intestinal polypectomy performed on an 11-year-old child with PJS, and do not expect her to have to undergo laparotomies.
\end{abstract}

Keywords: Peutz-Jeghers syndrome; Double balloon enteroscopy; Polypectomy

\section{Introduction}

Peutz-Jeghers syndrome (PJS) is an autosomal dominant inherited disease, characterized by multiple gastointestinal (GI) hamartomatous polyps and mucocutaneous pigmentation [1, 2]. To date, patients suffering from this condition have had to undergo frequent laparotomies because of intestinal obstruction by small intestinal polyps. Double-balloon enteroscopy (DBE) is now a useful device for the diagnosis

Manuscript accepted for publication September 5, 2011

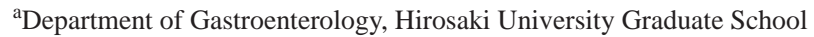

of Medicine, Hirosaki, Japan

${ }^{\mathrm{b}}$ Department of Medical Informatics, Hirosaki University Hospital,

Hirosaki, Japan

${ }^{\mathrm{c} D e p a r t m e n t ~ o f ~ P a t h o l o g y ~ a n d ~ B i o s c i e n c e, ~ H i r o s a k i ~ U n i v e r s i t y ~}$

Graduate School of Medicine, Hirosaki, Japan

${ }^{\mathrm{d}}$ Corresponding author: Tadashi Shimoyama, Department of

Gastroenterology, Hirosaki University Graduate School of Medicine,

5 Zaifu-cho, Hirosaki, 036-8562 Aomori, Japan.

Email: tsimo-hki@umin.ac.jp

doi:10.4021/jmc309w and treatment of small intestinal diseases [3]. Some studies have demonstrated successful endoscopic treatment of small intestinal polyps in adults with PJS [4-7]. We now report a successful use of DBE in the case of small intestinal polypectomy performed on an 11-year-old female child with PJS, and do not expect her to have to undergo unnecessary laparotomies in the future.

\section{Case Report}

An 11-year-old female child visited our hospital because of iron-deficient anemia (Hb 8.4 g/dL, MCV $60.8 \mathrm{fl}$ ) and frequent abdominal pain after meals. Her grandfather and mother had previously been diagnosed as PJS and have received laparotomies previously for intussusception of small intestinal polyps. Recently, her mother underwent small intestinal polypectomy using DBE in our hospital. The child, however, had no past history although she had pigmentation on her lips and toes, suggesting PJS (Fig. 1).

Initially, we performed endoscopic polypectomy for colorectal polyps, using intravenous analgesics (pentazocine $15 \mathrm{mg}$ and hydroxyzine $25 \mathrm{mg}$ ). Three polyps were resected, the largest being $2 \mathrm{~cm}$ in size. The pathology was compatible with PJ-type polyps. Two weeks later, the patient underwent oral DBE after obtaining informed consent. We performed DBE carefully in the same manner as we would for an adult,

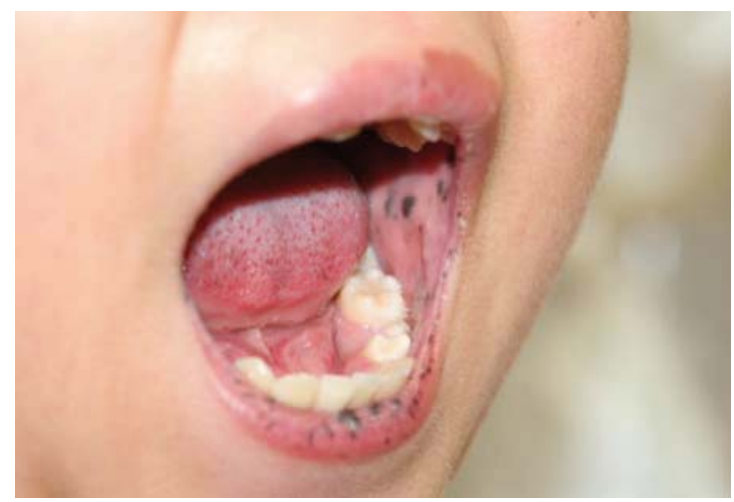

Figure 1. Pigmentation on the lips and the oral mucosa. 


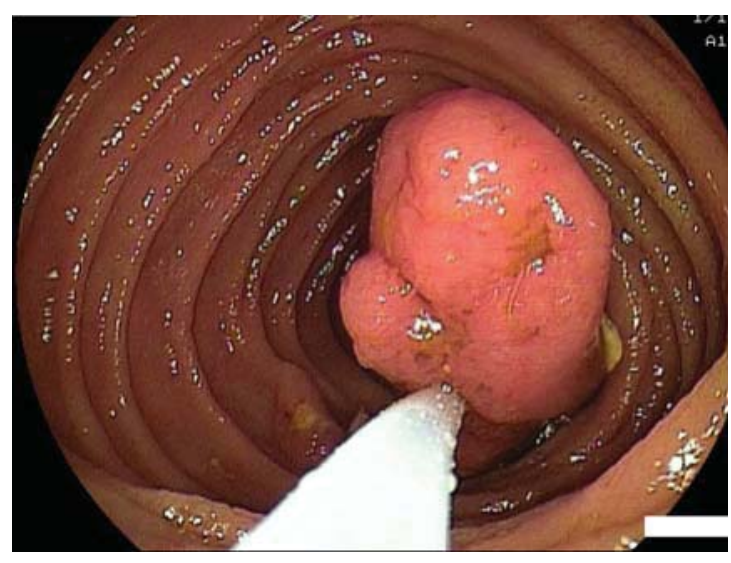

Figure 2. Removal of the polyp in the jejunum using DBE.

except under general anesthesia. Many polyps were found in the jejunum, the largest $3 \mathrm{~cm}$ in size (Fig. 2). Almost all the polyps were pedunculated, and 10 polyps were removed. In view of the low rates of carcinomatous change of PJ-type polyps [8], we retrieved only 2 large polyps in order to obtain pathological samples. The pathology revealed that these polyps were compatible with the PJ-type polyps, and had no adenomatous or carcinomatous components (Fig. 3). Although small polyps remained in the ileum, patient's family did not want removal at that time. She was well after the polypectomy and discharged 6 days later.

\section{Discussion}

One of the characteristic features of PJS is many GI polyps, particurally in the jejunum and the ileum $[1,2]$. Since there were no therapeutic strategies for PJS except surgery prior to the advent of DBE, frequent laparotomies were needed. Pathologically, PJ-type polyps are mostly hamartomatous, and those less than $3 \mathrm{~cm}$ in size have a low risk of carcinomatous changes [8]. If the polyps are resected without laparotomies, patients appear to have no need of surgery.

DBE is now available for the diagnosis and treatment of small intestinal diseases [3]. Some studies have revealed that DBE is useful to PJS, but primarily for adults [4-7]. However, it is sometimes necessary for children to undergo surgery. To date, only several children have underwent polypectomy using DBE [9]. In an infant, perforation was reported due to adhesion after polypectomy. PJS in children is associated with a high recurrence rate of small intestinal polyps in short-term follow-ups [10]. In our patient, 2 years after the first polypectomy mentioned above, we performed polypectomy safely from the anus with DBE. She appeared to have no abdominal adhesion. Our patient is approximately $140 \mathrm{~cm}$ in height and $47 \mathrm{~kg}$ in weight, which are within the mean \pm 2 SD of Japanese children of the same age. In cases in which adhesion occurs following laparotomies, we often

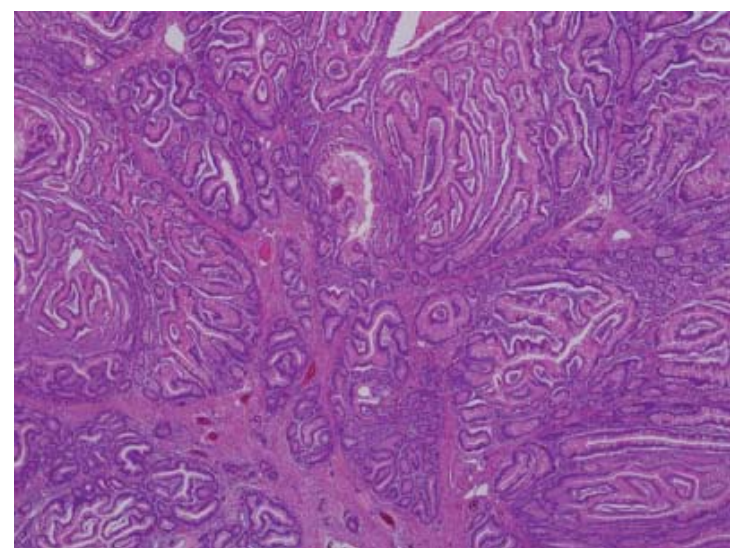

Figure 3. Pathology of the resected polyp. The polyp was compatible with the PJ-type and no adenomatous or carcinomatous components were found.

experience difficulty in inserting the scope into the small intestine. In such conditions, it is preferable to perform DBE in patients with PJS prior to surgery. The present case reveals that repeated polypectomy with DBE is safe and useful for PJS, even in children.

By perfoming repeated polypectomy with DBE, we expect that in the future there will no longer be a need for unnecessary laparotomies in case of PJS.

\section{References}

1. Peutz JLA. Very remarkable case of familial polyposis of mucous membrane of intestinal tract and nasopharynx accompanied by peculiar pigmentation of skin and mucous membrane. Ned Maandschr Geneeskd 1921; 10: $134-46$.

2. Jeghers H, Mc KV, Katz KH. Generalized intestinal polyposis and melanin spots of the oral mucosa, lips and digits; a syndrome of diagnostic significance. N Engl J Med. 1949;241(26):1031-1036.

3. Yamamoto H, Sekine Y, Sato Y, Higashizawa T, Miyata $\mathrm{T}$, Iino S, Ido K, et al. Total enteroscopy with a nonsurgical steerable double-balloon method. Gastrointest Endosc. 2001;53(2):216-220.

4. Ohmiya N, Taguchi A, Shirai K, Mabuchi N, Arakawa D, Kanazawa H, Ozeki M, et al. Endoscopic resection of Peutz-Jeghers polyps throughout the small intestine at double-balloon enteroscopy without laparotomy. Gastrointest Endosc. 2005;61(1):140-147.

5. Terauchi S, Snowberger N, Demarco D. Double-balloon endoscopy and Peutz-Jeghers syndrome: a new look at an old disease. Proc (Bayl Univ Med Cent). 2006;19(4):335-337.

6. Gao H, van Lier MG, Poley JW, Kuipers EJ, van Leer- 
dam ME, Mensink PB. Endoscopic therapy of smallbowel polyps by double-balloon enteroscopy in patients with Peutz-Jeghers syndrome. Gastrointest Endosc. 2010;71(4):768-773.

7. Ullerich H, Maaser C, Domschke W, Kucharzik T. Small intestinal obstruction by a Peutz-Jeghers polyp--doubleballoon enteroscopic removal. Endoscopy. 2007;39 Suppl 1:E193.

8. Beggs AD, Latchford AR, Vasen HF, Moslein G, Alonso A, Aretz S, Bertario L, et al. Peutz-Jeghers syndrome: a systematic review and recommendations for management. Gut. 2010;59(7):975-986.

9. Spahn TW, Kampmann W, Eilers M, Mueller MK, Rodeck B. Small-bowel perforation after endoscopic resection of a Peutz-Jeghers polyp in an infant using double-balloon enteroscopy. Endoscopy. 2007;39 Suppl 1:E217.

10. Taguchi T, Suita S, Taguchi S, Tanaka S. Peutz-Jeghers syndrome in children: high recurrence rate in short-term follow-up. Asian J Surg. 2003;26(4):221-224. 